\title{
Management of Spontaneous Intracerebral Hemorrhage
}

\author{
Roland Veltkamp ${ }^{1,2}$ • Jan Purrucker ${ }^{2}$
}

Published online: 8 September 2017

(C) The Author(s) 2017. This article is an open access publication

\begin{abstract}
Purpose of Review We review the current evidence for medical and surgical treatments of spontaneous intracerebral hemorrhage (ICH).

Recent Findings Therapy with hemostatic agents (e.g. factor VIIa and tranexamic acid) if started early after bleeding onset may reduce hematoma expansion, but their clinical effectiveness has not been shown. Rapid anticoagulation reversal with prothrombin concentrates (PCC) plus vitamin $\mathrm{K}$ is the first choice in vitamin $\mathrm{K}$ antagonist-related ICH. In ICH related to dabigatran, anticoagulation can be rapidly reversed with idarucizumab. PCC are recommended for ICH related to FXa inhibitors, whereas specific reversal agents are not yet approved. While awaiting ongoing trials studying minimally invasive approaches or hemicraniectomy, the role of surgery in ICH remains to be defined. Therapies targeting downstream molecular cascades in order to prevent secondary neuronal damage are promising, but the complexity and multi-phased nature of ICH pathophysiology is challenging. Finally, in addition to blood pressure control, antithrombotic prevention after ICH has to consider the risk of recurrent bleeding as well as the risk of ischemic events.

Summary Treatment of acute ICH remains challenging, and many promising interventions for acute $\mathrm{ICH}$ await further evidence from trials.
\end{abstract}

This article is part of the Topical Collection on Stroke

Roland Veltkamp

r.veltkamp@imperial.ac.uk

1 Department of Stroke Medicine, Imperial College London, Charing Cross Campus, 3 East 6, London W6 8RF, UK

2 Department of Neurology, Heidelberg University Hospital, Heidelberg, Germany
Keywords Hematoma growth · Hemostatic therapy · Antihypertensive $\cdot$ Anticoagulation

\section{Introduction}

Spontaneous, non-traumatic intracerebral hemorrhage (ICH) accounts for $10-15 \%$ of all strokes, but its contribution to overall stroke mortality and disability is over-proportionally high [1]. Fifty-eight percent of ICH patients die within 1 year, and $2 / 3$ of survivors remain moderately or even severely disabled [2]. Various forms of cerebral small vessel diseases underlie the majority of spontaneous ICH. Additional causes include vascular malformations, cerebral sinus vein thrombosis, tumors, vasculitis, and antithrombotic medication.

The prognosis and pathophysiology of ICH are increasingly better understood. In addition to non-modifiable prognostic patient characteristics such as age and pre-morbid disability including cognitive deficits, the clinical presentation and the size of the hematoma are crucial prognostic factors [3]. Importantly, hematoma size is dynamic particularly in the first hours after the event. About one-third of ICH patients presenting within the first 3-6 h after symptom onset will have hematoma growth which worsens outcome [4]. Hence, prevention of hematoma growth has become a key target of early ICH management. Another important, but more delayed process is the development of peri-hematomal edema which contributes substantially to the space-occupying effect of the hematoma. Compared to ischemic stroke, posthemorrhagic edema may have different kinetics. Edema onset begins later according to some but not all reports $[5,6]$, and post-hemorrhagic edema resolves only after weeks. Extravasated blood components including heme, iron, and thrombin in the brain trigger several toxic and inflammatory cascades that contribute substantially to edema and secondary brain cell damage. 
With better insights into the pathophysiology of acute ICH, medical and surgical treatment options for ICH have been under intense investigation over the last 10 years. There is good evidence that, similar to ischemic stroke, management of ICH patients on specialized multidisciplinary stroke units or neuro-critical care units improves outcome [7]. In contrast, current treatment guidelines for ICH reflect that many aspects of ICH management have remained vague even after publication of large clinical trials. In some areas, evidence is mounting that interventions are not only ineffective but rather harmful, and should hence be avoided.

In the present review, we will summarize recent evidence regarding hemostatic, antihypertensive, surgical, and neuroprotective management of $\mathrm{ICH}$. We also describe ongoing efforts to tackle the challenges of ICH management and provide an outlook to where the field is heading.

\section{Prevention of Hematoma Growth}

Hematoma growth occurs predominantly during the first few hours after ICH onset, but delayed hematoma growth can happen particularly in anticoagulated patients (see subsequent texts). The mechanisms underlying hematoma growth are not entirely clear. Consistent with a proposal originally made by Miller-Fisher based on his histopathological findings, the initial hematoma leads to twisting of the surrounding tissues which predisposes other potentially diseased microvessels to tear successively and thereby produce a "hemorrhagic avalanche" $[8,9]$. Interestingly, the "avalanche" hypothesis is supported by an association between the apolipoprotein $\mathrm{E}$ (APOE) epsilon 2 allele, itself linked to an increased fragility of vessel walls, and hematoma expansion in lobar ICH [10]. Additional therapeutically amenable forces predisposing to continued bleeding include a raised arterial blood pressure and a deficiency of hemostatic factors.

\section{Blood Pressure}

Lowering arterial blood pressure in acute ICH has been studied in several trials. Smaller phase 2 trials suggested that lowering blood pressure below $140 \mathrm{mmHg}$ within $1 \mathrm{~h}$ in ICH patients admitted within $6 \mathrm{~h}$ after symptom onset is safe and may improve outcome and reduce the risk of hematoma expansion [11, 12]. Subsequently, two large phase 3 RCTs were performed. The INTERACT-2 trial examined the effect of intensive systolic blood pressure lowering $(<140 \mathrm{mmHg}$ ) compared to standard treatment $(<180 \mathrm{mmHg})$ on death and major disability (modified Rankin Scale (mRS) 3-6) [13•]. One hour after randomization, the blood pressure target was achieved in only one-third of the patients in the intensive treatment group. At 3 months, there was a strong trend for the primary endpoint in favor of intensive blood pressure lowering, and there was a statistically significant effect on the ordinal analysis of the modified Rankin scale score, a secondary endpoint. In contrast, neither hematoma growth (35.1 vs. $33.1 \%$ ) nor mortality (11.9 vs. $12 \%$ ) differed significantly between groups [13•]. As only a minority of patients suffered anticoagulation-related ICH (2.9\%), results cannot be generalized to this important ICH subgroup. Based on the INTERACT-2 trial, the current AHA/ASA guideline states that blood pressure lowering to $140 \mathrm{mmHg}$ or lower is safe and can be effective to improve functional outcome [14].

In the multicenter ATACH2-trial, ICH patients with a Glasgow Coma Scale of 5 or more were randomized within a $4.5 \mathrm{~h}$ time window to an intensive systolic blood pressure target of 110 to $139 \mathrm{mmHg}$ or a "standard" target of 140 to $179 \mathrm{mmHg}\left[15^{\circ}\right]$. The primary endpoint of the trial was the dichotomized mRS score (0-3 vs. 4-6). Besides a prespecified rescue-therapy if systolic blood pressure exceeded the target for $30 \mathrm{~min}$, only nicardipine infusion was allowed to manage blood pressure [15•]. The trial was stopped due to futility after enrolment of 1000 patients (intensive lowering mRS $4-6 ; 38.7$ vs. $37.7 \%$ in standard treatment) [15•]. There was no difference in the rate of hematoma expansion [15•]. The mean standard treatment group minimum systolic blood pressure was $141 \mathrm{mmHg}$ after $2 \mathrm{~h}$, compared to $129 \mathrm{mmHg}$ in the intensive treatment group. Thus, it is likely that the neutral results of the trial were a result of the already very good blood pressure management in the group receiving standard treatment. Notably, renal adverse events were more common in the intensive treatment group which may argue for less aggressive blood pressure lowering.

Blood pressure lowering is likely to be relevant also in anticoagulant-related ICH (see subsequent texts). In 853 patients with vitamin $\mathrm{K}$ antagonist (VKA)-related ICH, an increased rate of hematoma expansion in patients with systolic blood pressure $>=160 \mathrm{mmHg}(52.4 \%)$ compared to $<160 \mathrm{mmHg}(33.1 \%)$, assessed $4 \mathrm{~h}$ after admission, was found [16•]. Blood pressure lowering to $<160 \mathrm{mmHg}$ was associated with a reduction of in-hospital mortality.

\section{Hemostatic Factors}

Stopping the expanding bleeding by enhancing blood clot formation at the site around the vessel rupture is an attractive therapeutic concept. Recombinant factor VIIa is a particularly potent agent as it is activated by tissue factor, a protein that is abundant in brain and exposed upon vascular injury. The initial phase 2 NovoSeven trial found a substantial benefit of factor VIIa over placebo in terms of hematoma growth and clinical outcome when administered within $4 \mathrm{~h}$ after symptom onset [17]. The subsequent FAST trial confirmed the preventive effect of rFVIIa $(80 \mu \mathrm{g} / \mathrm{kg}$ body weight) on hematoma growth but failed to show a clinical benefit [18]. This lack of clinical benefit was partially driven by an excess of 
thromboembolic events in the rFVIIa group resulting from its prothrombotic effect $[18,19]$. A potential resolution of this dilemma of promoting hemostasis and the adverse thromboembolic events may be to improve the selection of patients to the population that has the highest likelihood of benefit from hemostasis (i.e. patients at high risk of hematoma expansion). Such an indicator of an increased risk of hematoma growth may be the "spot sign" which reflects contrast extravasation on post-contrast CT scans [20]. Patients with a spot sign had a 2.6-fold higher risk of hematoma expansion in one study [21], but a recent sub-analysis of the ATACH-II trial challenges the predictive power of the spot-sign [22]. Hypodensities within an ICH on non-contrast CT were also recognized as an independent sign of hematoma expansion [23]. Potential other non-contrast $\mathrm{CT}$ imaging markers associated with hematoma expansion include the blend sign (i.e. hypoattenuating areas adjacent to hyperattenuation within $\mathrm{ICH}$ ) and the swirl sign $[24,25]$. The SPOTLIGHT and STOP-IT trials enrolled nonanticoagulated ICH patients presenting within $6 \mathrm{~h}$ after symptom onset who had a spot sign on baseline $\mathrm{CT}$ imaging. Both trials had slow recruitment, and the recently presented joint analysis included only 142 patients [26.]. The rate of hematoma expansion was low in the trials, and no significant difference was found between treated and untreated patients.

Another promising hemostatic agent is tranexamic acid (TXA) which promotes hemostasis by blocking plasminogen binding to fibrin. Importantly, there is some evidence from the CRASH-2 trial, a large RCT in major trauma patients, that tranexamic acid reduces mortality [27]. The CRASH-3 trial, focusing on the effects of TXA in traumatic brain injury, is ongoing. At present, several RCTs investigate the potential of tranexamic acid also in spontaneous ICH. The Tranexamic acid for hyperacute primary IntraCerebral Hemorrhage (TICH-2) trial is an RCT which will enroll up to 2400 patients with spontaneous ICH presenting within $8 \mathrm{~h}$ after symptom onset. Patients are randomized to receive TXA ( $1 \mathrm{~g}$ bolus followed by infusion of $1 \mathrm{~g}$ over $8 \mathrm{~h}$ ) or placebo. Results are expected in 2018. The ongoing STOP-AUST trial selects ICH patients for TXA vs placebo based on the spot sign. The trial aims to enroll 100 patients, and results are expected later in 2018. Additional trials with TXA in ICH include the placebo-controlled Tranexamic Acid for Acute ICH Growth prEdicted by Spot Sign trial (TRAIGE; clinicaltrials.gov NCT02625948), the Tranexamic Acid for Spontaneous Acute Cerebral Hemorrhage Trial (TRANSACT; NCT03044184), and the Romanian Emergency Management of Spontaneous Intracerebral Hemorrhage (EsICH) study. Furthermore, the Swiss TICH-NOAC trial (NCT02866838) specifically focuses on efficacy of TXA in patients suffering NOAC-related ICH. Alternative hemostatic agents are in early-phase clinical development. In the phase 1b Pfizer ICH trial (clinicaltrials.gov, NCT02687191), the safety of a recombinant factor Xa (PF$05230907)$ is tested. This $\mathrm{rFXa}\left(\mathrm{FXa}^{\mathrm{Il}}{ }^{\mathrm{L}}\right)$ is more resistant to inactivation by plasma protease inhibitors compared to endogenous FXa [28]. While the study excludes patients with known anticoagulation, the FXa variant was shown to effectively overcome the anticoagulant effects of the FXa-inhibitor rivaroxaban as well as the direct thrombin inhibitor dabigatran in an experimental study [29]. Specific reversal agents for NOACs are discussed subsequently.

\section{Anticoagulant-Related ICH}

Because of their much better efficacy than antiplatelets, oral anticoagulants $(\mathrm{OAC})$ are increasingly used for long-term primary and secondary prevention of stroke and systemic embolism in patients with atrial fibrillation and less frequently in other indications including mechanical heart valves. The flip side of their increasing use is hemorrhagic complications. Among these, ICH is the most feared complication of long-term anticoagulation. Although extracranial major bleedings are 5to 10 -fold more frequent, ICH accounts for $58 \%$ of all bleeding-associated deaths in anticoagulated patients [30]. In population-based studies, ICH related to OAC accounts for 10$15 \%$ of all ICHs, but this proportion increases to $25 \%$ in tertiary stroke centers [31]. Anticoagulant-related ICH has a higher mortality than ICH in patients not treated with anticoagulation or antithrombotic therapy [32]. Hematoma growth occurs more frequently in patients anticoagulated with VKA, and growth is more likely to occur over a prolonged period than in nonanticoagulated patients [33]. The excess risk of hematoma expansion is the rationale for immediate anticoagulation reversal in VKA-ICH. Table 1 provides a brief overview over the most relevant non-OAC and OAC-related ICH studies analyzing baseline hematoma volume and expansion.

\section{Vitamin K Antagonists}

VKA anticoagulate via inhibiting the synthesis of vitamin Kdependent coagulation factors in the liver (i.e. factors II, VII, IX, X, protein C and S). Rapid replacement of deficient coagulation factors in case of bleeding is the preferred method of anticoagulation reversal. Substitution of vitamin $\mathrm{K}$ also reverses anticoagulation, but it is not suitable for immediate reversal of VKA, as measurable effects take hours to days. Prothrombin concentrates (PCC) and fresh frozen plasma (FFP) were the most frequently considered options for reversal in the past. In contrast to FFP which are stored in blood banks, PCC are readily available, do not need compatibility testing before transfusion, and can be infused over a few minutes. Infusion of FFPs requires infusion of large volumes which is time-consuming and can cause fluid overload. Recent RCTs have shown that PCC more rapidly and consistently reverse anticoagulation in patients with major bleeding $[34,35]$. In the INCH trial, a phase $2 \mathrm{RCT}$ enrolling 50 patients 


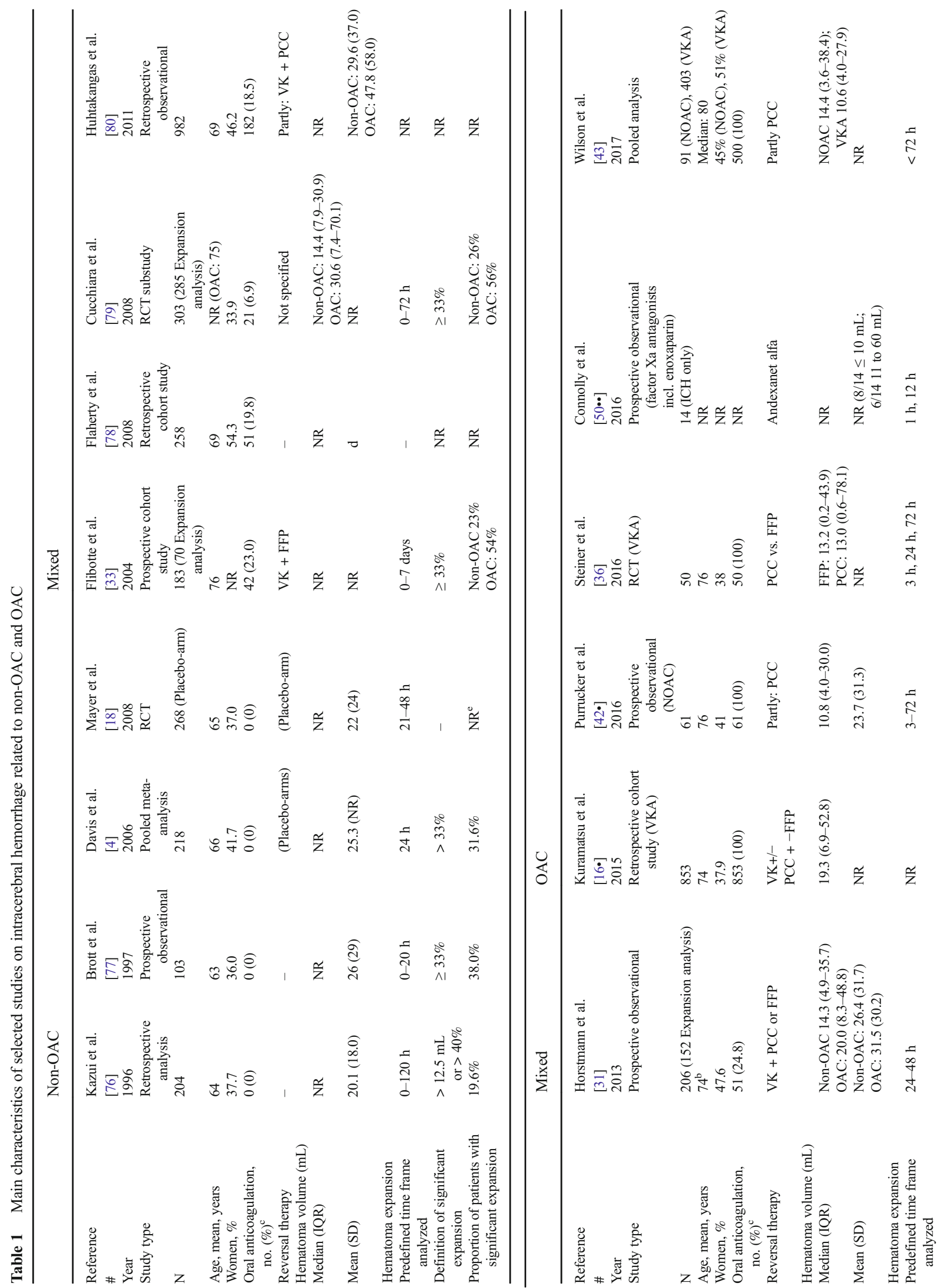


with intracranial hemorrhage, $\mathrm{PCC}$ also reduced the proportion of ICH patients with early hematoma growth and with early mortality attributed to hematoma growth [36••]. These findings are corroborated by the observational RETRACE study which found that risk of hematoma expansion was associated with the INR level after OAC reversal (RR 2.3; 95\% CI 1.3-4.1; $p=0.005)$, but not the initial INR obtained at admission [16 ${ }^{\bullet}$. Patients who achieved an INR $<1.3$ had significantly fewer rates of hematoma expansion than those who did not (27 vs. $45 \%$, $p<0.001)$. Time until complete reversal of anticoagulation is essential as a beneficial effect of INR normalization was only observed until approximately $4 \mathrm{~h}$ after admission [16•]. Although efficacy of early reversal of anticoagulation by PCC in terms of functional outcome still remains to be shown, PCC are the preferred reversal agents in VKA-ICH. Reversal of VKA anticoagulation can be accelerated if the INR is tested and monitored during reversal using a point-of-care coagulometer in $\mathrm{ICH}$ patients [37]. Administration of coagulation factors including PCC carries a risk of triggering thromboembolic complications. However, in a retrospective study of 205 patients with $\mathrm{ICH}$, thromboembolism attributed to PCC was a rare occurrence [38]. Finally, in light of the limited half-life of coagulation factors, replacement of coagulation factors should always be accompanied by administration of vitamin $\mathrm{K}$ to enable hepatic synthesis of coagulation factors.

\section{Non-Vitamin K Antagonist Oral Anticoagulants}

NOACs comprise the direct thrombin inhibitor dabigatran and the factor Xa inhibitors apixaban, edoxaban, and rivaroxaban. NOACs have at least similar efficacy and are safer than VKA in terms of major bleeding for stroke prevention in AF [39]. Importantly, they carry about a $50 \%$ lower risk of intracranial hemorrhage compared to VKA [39]. Nevertheless, if NOACrelated ICH occurs, the outcome including mortality is similar to ICH associated with VKA [40, 41]. Initial case-series suggested that the risk of hematoma growth in NOAC-related ICH was not increased compared to non-anticoagulated patients. As larger series have refuted this observation, there is a rational for reversal of anticoagulation in NOAC-ICH [42•, 43]. Rapid diagnosis of anticoagulant intensity of NOACs depends largely on coagulation tests that are not part of routine coagulation testing so far [44]. Point-of-care coagulometry for NOACs is desirable to speed decisions on reversal, and a number of devices are currently under development [45].

Reversal agents specific to dabigatran and the factor $\mathrm{Xa}$ inhibitors, respectively, have been developed. The only currently licensed specific reversal agent is idarucizumab, a humanized Fab fragment binding to dabigatran. Bolus injection of idarucizumab rapidly reverses the anticoagulant effect of dabigatran in healthy volunteers [46], patients with renal failure [47], and patients with acute major bleedings including $\mathrm{ICH}[48 \bullet \bullet$. There is no evidence of prothrombotic effects. 
However, experience with idarucizumab in dabigatran-related ICH from the REVERSE-AD study is limited so far. In a murine model of $\mathrm{ICH}$, the Fab fragment reduces bleeding and mortality [49].

Factor Xa inhibitors can be rapidly reversed with an infusion of andexanet alfa, a recombinant, genetically modified FXa that has lost the pro-coagulant effect. The bolus is followed by a continuous infusion over $4 \mathrm{~h}$. Dosing of andexanet alfa depends on the FXa inhibitor used and the time since last intake [50••]. In the first data set of the ANNEXA-4 trial reported in late 2016, rapid reversal was accompanied by a partial rebound of the anticoagulant effect after the end of the infusion [50••]. The compound is not licensed yet, and the ANNEXA-4 trial continues with a focus on ICH.

The third specific reversal agent, ciraparantag, is a small molecule that binds all NOACs (and some other anticoagulants) via hydrogen bonds and charge-charge interactions [51]. Infusion of ciraparantag reverses the prolonged bleeding time in healthy subjects taking different NOACs, but information from later phase clinical studies on safety and efficacy is not available yet [52]. Interestingly, PCC have some capacity to reverse NOACs as well. They are currently recommended for reversal of FXa inhibitors in major bleeding including $\mathrm{ICH}$, but evidence for clinical efficacy in ICH is not available [53].

\section{Antiplatelets}

A relevant number of patients with ICH are taking antiplatelet medication at the time of the event. Cyclooxygenase inhibitors such as aspirin and the $\mathrm{P} 2 \mathrm{Y} 2 \mathrm{G}$ inhibitors clopidogrel, prasugrel, and ticagrelor irreversibly block their targets in platelets and thereby attenuate platelet aggregation. As availability of functional platelets appears desirable in critical bleeding events such as ICH, transfusion of platelets or stimulation of von-Willebrand factor release and platelet aggregation by desmopressin have been advocated [54]. The randomized PATCH trial investigated in 190 patients under antithrombotic treatment the effect of platelet transfusion within $6 \mathrm{~h}$ of acute supratentorial ICH. Surprisingly, the study revealed that platelet transfusions increased mortality or dependence at 3 months (adj. OR 2.1, $p=0.0114$ ) [55]. Hence, platelet transfusion should not be performed in ICH patients taking antiplatelet medication.

\section{Surgery}

Removal of the extravascular blood in the brain is a plausible strategy in ICH for various reasons. First, reducing the size of the intracerebral hematoma reduces its space-occupying effect. Beyond reducing the physical forces, removal of blood may also reduce toxic blood components that are released from lysed blood cells such as heme or are part of the blood plasma such as thrombin. Unless the space-occupying effect is immediately life threatening, surgical procedures are usually delayed for a few hours to reduce the risk of recurrent bleeding.

A previous systematic review and meta-analysis of surgical trials suggested a beneficial effect of surgery on mortality [56]. The randomized, controlled STICH trial investigated whether early surgery with hematoma evacuation within a maximum of 4 days is beneficial compared to standard treatment. Inclusion of patients was only possible if the local neurosurgeon was uncertain about the benefits of either treatment. The study failed to confirm a benefit of surgical clot removal [57]. Subsequently, the STICH-2 trial was performed based on a subgroup analysis of the STICH trial that had suggested a benefit of surgery for patients with lobar hematoma location. However, no benefit of early hematoma evacuation $(<12 \mathrm{~h}$ after randomization) was shown in STICH-2 for patients with lobar ICH [58].

More recent surgical approaches towards ICH aim to be less invasive. In the MISTIE program, a catheter is introduced via stereotactic guidance into the hematoma. In addition to blood drainage, small doses of rtPA are injected into the ventricles to liquefy the hematoma. The phase 2 MISTIE trial suggested that the procedure is safe and may be beneficial [59・•]. Results of the ongoing phase 3 MISTIE III trial (NCT01827046) are expected in 2018/9. A minimally invasive approach requiring only small craniotomies or burr holes to allow mechanical hematoma evacuation is currently investigated in a phase II trial (INVEST), and further studies are planned $[60,61]$.

Hemicraniectomy is another surgical approach that targets the space-occupying effect of the hematoma in analogy to the benefit observed in patients with malignant middle cerebral artery infarction. A small case series supported effectiveness of the approach in ICH, but further evidence from the SWITCH trial (NCT02258919) is necessary to evaluate the usefulness of the procedure.

Intraventricular hemorrhage (IVH) can occur in isolation or more frequently as part of parenchymal ICH where it is a negative prognostic factor [62]. A particular complication of IVH is blockage of the circulation of cerebrospinal fluid in the cerebral ventricles resulting in hydrocephalus. Placement of an external ventricular drain (EVD) is a standard procedure in this situation, but pure CSF drainage may not suffice if large volumes of blood obstruct the lateral ventricles or block the third and fourth ventricles. Moreover, prolonged presence of EVDs increases the risk of ventriculitis. Clot lysis can be accelerated by intraventricular injection of low doses of rtPA. Initial studies of the CLEAR-IVH program suggested that low-dose rtPA injection in IVH is safe [63]. In the recently published CLEAR-III trial, a dose-dependently better resolution of the intraventricular clot was observed in rt-PA patients, but this failed to affect overall outcome [64.•]. As post-hoc analyses suggested a benefit in patients with effective clot 
removal, a subsequent trial may focus on personalized dosing of the lytic based on close monitoring of clot removal in individual patients.

\section{Blocking Secondary Deleterious Toxic Processes}

Experimental evidence strongly suggests that numerous cellular and molecular cascades are triggered by extravascular blood in the brain which contribute to hemorrhagic brain injury. Key pathophysiological processes include intracellular calcium release due to thrombin-mediated activation of protease-activated receptors and toll-like receptor 4 activation by fibrinogen and heme via microglia activation which leads to activation of transcription factors and expression of proinflammatory cytokines [65-68]. Erythrocyte damage releases iron, and particularly iron not bound to heme is associated with free radical formation, brain edema, and secondary neuronal death [69]. Deferoxamin, a potent iron chelator reduced post-ICH edema formation and improved functional outcome in experimental ICH [69]. This has been translated into the ongoing phase 2 Intracerebral Hemorrhage Deferoxamine (iDEF) trial (NCT02175225). The RCT aims to enroll 294 patients to receive either deferoxamin within $24 \mathrm{~h}$ of ICH onset for 3 days or placebo. The primary endpoint is "good functional outcome" (mRS 0-2) at 90 days. Results are expected in late 2018.

nflammation is now recognized as an essential component contributing to acute brain damage and repair [68]. The initial local response in the brain is triggered by release of danger-associated molecular patterns (DAMPs) from injured brain cells [65]. These DAMPs rapidly activate microglia which secrete toxic proinflammatory cytokines including IL1-beta and IL6 and chemokines that attract systemic immune cells. However, microglia and infiltrating macrophages also play important roles in clearing up blood components and potentially repair. By upregulating adhesion molecules, activated endothelial cells in the cerebral microvasculature facilitate entry of systemic immune cells including neutrophils, macrophages, and lymphocytes. Initially, these immigrating cells predominantly augment brain damage, but in later phases, their effects comprise repair and down-regulation of inflammation. Clinical studies targeting the inflammatory systems in ICH have addressed key cytokines (IL-1a), microglia, immigrating neutrophils, and T cells [68]. An advantage for translational medicine addressing immune cells in ICH is that a constantly growing toolbox of established medicines for other primary inflammatory conditions allows translation across traditional disease classes. For example, a small pilot study using repetitive MRI scanning to examine the effects of the sphingosine-1-receptor blocker fingolimod which reduces lymphocyte egress from lymphatic organs suggested a reduction in brain edema and better clinical outcome [70]. Clearly, a better understanding of the multi-phased pathophysiology of inflammation in ICH and subsequent later phase clinical trials are needed.

\section{Stroke Prevention after ICH}

The primary concern after a devastating event such as ICH is to prevent recurrence. However, a relevant proportion of ICH patients are simultaneously at increased risk of ischemic disease including myocardial infarction and stroke. About 34\% of non-anticoagulated patients are already taking a single or even dual antiplatelet agent [71]. Another 15-20\% of ICH patients have an indication for long-term anticoagulation, usually because of atrial fibrillation, with $90 \%$ of them having a $\mathrm{CHA}_{2} \mathrm{DS}_{2} \mathrm{VAS}_{\mathrm{c}}$ score of 2 or greater. Preventive management of these patients has to weigh the benefits as well as the risks of prescribing or withholding antithrombotic therapy. According to a systematic review examining the effect of antiplatelet therapy after $\mathrm{ICH}$, there is insufficient evidence to either support or withhold antiplatelet therapy [70]. The ongoing randomized controlled REstart or STop Antithrombotic Randomized Trial (NCT02966119) will provide essential information for best management in this setting. For ICH patients with AF, evidence from meta-analyzed recent large observational trials suggests a much higher annual rate of ischemic stroke than for recurrent ICH. Anticoagulation with VKA reduces the rate of thromboembolic complications, apparently without increasing the rate of recurrent ICH significantly, and also reduced mortality [72]. This benefit may even have been greater in patients treated with NOACs. However, the underlying observational studies have methodological limitations including confounding by indication, and therefore, a randomized controlled trial is needed to resolve the uncertainty. Eventually, management in this complex situation will have to be personalized, and decision-making will include individual patient factors such as the severity of cerebral small vessel disease and cerebral microbleeds.

Hypertension is a key risk factor for ICH and ICH recurrence. In addition to absolute values of systolic and diastolic blood pressure, blood pressure variability influences the risk. Normalizing blood pressure is a main goal of preventive management. The PROGRESS trial found lowest recurrent stroke rate in patients with lowest blood pressure during follow-up [73]. Intensive BP lowering in patients with recent lacunar stroke was of greatest benefit in terms of ICH reduction in the SPS3 trial, while no reduction in ischemic stroke was found [74]. Better monitoring of blood pressure targets potentially by using telemedicine approaches is likely to improve 
blood pressure control and potentially stroke prevention (PROHIBIT-ICH) [75].

\section{Conclusions}

Many promising interventions for acute ICH await further evidence from trials. Hemostatic therapy is most likely to be effective in the early hours after symptom-onset patients at high risk of hematoma growth. Rapid anticoagulation reversal is indicated in anticoagulant-related ICH, but more evidence regarding clinical efficacy is desirable. Future surgical and interventional management of ICH will focus on minimally invasive techniques. Therapies targeting downstream molecular and cellular processes are desirable, but the complexity and frequently multi-phased nature of pathophysiological processes require better understanding. When choosing appropriate secondary prevention after ICH in addition to blood pressure control, the strategy should consider prevention of recurrent bleeding as well as the frequently increased risk of thromboembolic ischemic events.

Acknowledgments Roland Veltkamp is an investigator of the NIHR Imperial Biomedical Research Centre.

\section{Compliance with Ethical Standards}

Conflict of Interest Roland Veltkamp reports grants from the Boehringer Ingelheim, Bayer, BMS, Daiichi Sankyo, and Biogen. Dr. Veltkamp reports personal fees from the PHRI-Portola, Boehringer Ingelheim, Bayer, BMS, Daiichi Sankyo, and Biogen.

Jan Purrucker reports personal fees from Pfizer and Boehringer Ingelheim.

Human and Animal Rights and Informed Consent This article does not contain any studies with human or animal subjects performed by any of the authors.

Open Access This article is distributed under the terms of the Creative Commons Attribution 4.0 International License (http:// creativecommons.org/licenses/by/4.0/), which permits unrestricted use, distribution, and reproduction in any medium, provided you give appropriate credit to the original author(s) and the source, provide a link to the Creative Commons license, and indicate if changes were made.

\section{References}

Papers of particular interest, published recently, have been highlighted as:

- Of importance

•- Of major importance

1. Sacco S, Marini C, Toni D, Olivieri L, Carolei A. Incidence and 10year survival of intracerebral hemorrhage in a population-based registry. Stroke. 2009;40(2):394-9. https://doi.org/10.1161/ STROKEAHA.108.523209.

2. Fogelholm R, Murros K, Rissanen A, Avikainen S. Long term survival after primary intracerebral haemorrhage: a retrospective population based study. J Neurol Neurosurg Psychiatry. 2005;76(11):1534-8. https://doi.org/10.1136/jnnp.2004.055145.

3. Broderick JP, Brott TG, Duldner JE, Tomsick T, Huster G. Volume of intracerebral hemorrhage. A powerful and easy-to-use predictor of 30-day mortality. Stroke. 1993;24(7):987-93.

4. Davis SM, Broderick J, Hennerici M, Brun NC, Diringer MN, Mayer SA, et al. Hematoma growth is a determinant of mortality and poor outcome after intracerebral hemorrhage. Neurology. 2006;66(8):1175-81. https://doi.org/10.1212/01.wnl.0000208408. 98482.99.

5. Venkatasubramanian C, Mlynash M, Finley-Caulfield A, Eyngorn I, Kalimuthu R, Snider RW, et al. Natural history of perihematomal edema after intracerebral hemorrhage measured by serial magnetic resonance imaging. Stroke. 2011;42(1):73-80. https://doi.org/10. 1161/STROKEAHA.110.590646.

6. Wu TY, Sharma G, Strbian D, Putaala J, Desmond PM, Tatlisumak $\mathrm{T}$, et al. Natural history of perihematomal edema and impact on outcome after intracerebral hemorrhage. Stroke. 2017;48(4):8739. https://doi.org/10.1161/STROKEAHA.116.014416.

7. Langhorne P, Fearon P, Ronning OM, Kaste M, Palomaki H, Vemmos K, et al. Stroke unit care benefits patients with intracerebral hemorrhage: systematic review and meta-analysis. Stroke. 2013;44(11):3044-9. https://doi.org/10.1161/STROKEAHA.113. 001564.

8. Fisher CM. Pathological observations in hypertensive cerebral hemorrhage. J Neuropathol Exp Neurol. 1971;30(3):536-50.

9. Brouwers HB, Greenberg SM. Hematoma expansion following acute intracerebral hemorrhage. Cerebrovasc Dis. 2013;35(3): 195-201. https://doi.org/10.1159/000346599.

10. Brouwers HB, Biffi A, Ayres AM, Schwab K, Cortellini L, Romero $\mathrm{JM}$, et al. Apolipoprotein E genotype predicts hematoma expansion in lobar intracerebral hemorrhage. Stroke. 2012;43(6):1490-5. https://doi.org/10.1161/STROKEAHA.111.643262.

11. Qureshi AI, Palesch YY, Martin R, Novitzke J, Cruz-Flores S, Ehtisham A, et al. Effect of systolic blood pressure reduction on hematoma expansion, perihematomal edema, and 3-month outcome among patients with intracerebral hemorrhage: results from the antihypertensive treatment of acute cerebral hemorrhage study. Arch Neurol. 2010;67(5):570-6. https://doi.org/10.1001/ archneurol.2010.61.

12. Anderson CS, Huang Y, Wang JG, Arima H, Neal B, Peng B, et al. Intensive blood pressure reduction in acute cerebral haemorrhage trial (INTERACT): a randomised pilot trial. Lancet Neurol. 2008;7(5):391-9. https://doi.org/10.1016/S1474-4422(08)700693.

13. Anderson CS, Heeley E, Huang Y, Wang J, Stapf C, Delcourt C, et al. Rapid blood-pressure lowering in patients with acute intracerebral hemorrhage. N Engl J Med. 2013;368(25):2355-65. https:// doi.org/10.1056/NEJMoa1214609. Important RCT on blood pressure lowering suggesting a benefit of more stringent blood pressure targets in acute $\mathrm{ICH}$.

14. Hemphill JC 3rd, Greenberg SM, Anderson CS, Becker K, Bendok BR, Cushman M, et al. Guidelines for the management of spontaneous intracerebral hemorrhage: a guideline for healthcare professionals from the American Heart Association/American Stroke Association. Stroke. 2015;46(7):2032-60. https://doi.org/10.1161/ STR.0000000000000069.

15. Qureshi AI, Palesch YY, Barsan WG, Hanley DF, Hsu CY, Martin $\mathrm{RL}$, et al. Intensive blood-pressure lowering in patients with acute cerebral hemorrhage. N Engl J Med. 2016;375(11):1033-43. https://doi.org/10.1056/NEJMoa1603460. Important RCT 
raising safety concerns regarding renal function by intensive blood pressure lowering in acute ICH.

16. Kuramatsu JB, Gerner ST, Schellinger PD, Glahn J, Endres M, Sobesky J, et al. Anticoagulant reversal, blood pressure levels, and anticoagulant resumption in patients with anticoagulationrelated intracerebral hemorrhage. JAMA. 2015;313(8):824-36. https://doi.org/10.1001/jama.2015.0846. Large observational study supporting rapid blood pressure lowering and anticoagulation reversal in acute vitamin $K$ antagonist associated $\mathrm{ICH}$.

17. Mayer SA, Brun NC, Begtrup K, Broderick J, Davis S, Diringer $\mathrm{MN}$, et al. Recombinant activated factor VII for acute intracerebral hemorrhage. N Engl J Med. 2005;352(8):777-85. https://doi.org/ 10.1056/NEJMoa042991.

18. Mayer SA, Brun NC, Begtrup K, Broderick J, Davis S, Diringer $\mathrm{MN}$, et al. Efficacy and safety of recombinant activated factor VII for acute intracerebral hemorrhage. N Engl J Med. 2008;358(20): 2127-37. https://doi.org/10.1056/NEJMoa0707534.

19. Al-Shahi SR. Haemostatic drug therapies for acute spontaneous intracerebral haemorrhage. Cochrane Database Syst Rev. 2009;4: CD005951. https://doi.org/10.1002/14651858.CD005951.pub3.

20. Goldstein JN, Fazen LE, Snider R, Schwab K, Greenberg SM, Smith EE, et al. Contrast extravasation on $\mathrm{CT}$ angiography predicts hematoma expansion in intracerebral hemorrhage. Neurology. 2007;68(12):889-94. https://doi.org/10.1212/01.wnl.0000257087. 22852.21.

21. Demchuk AM, Dowlatshahi D, Rodriguez-Luna D, Molina CA, Blas YS, Dzialowski I, et al. Prediction of haematoma growth and outcome in patients with intracerebral haemorrhage using the CTangiography spot sign (PREDICT): a prospective observational study. Lancet Neurol. 2012;11(4):307-14. https://doi.org/10.1016/ S1474-4422(12)70038-8.

22. Morotti A, Brouwers HB, Romero JM, Jessel MJ, Vashkevich A, Schwab K, et al. Intensive blood pressure reduction and spot sign in intracerebral hemorrhage: a secondary analysis of a randomized clinical trial. JAMA Neurol. 2017; https://doi.org/10.1001/jamaneurol.2017. 1014.

23. Boulouis G, Morotti A, Brouwers HB, Charidimou A, Jessel MJ, Auriel E, et al. Association between hypodensities detected by computed tomography and hematoma expansion in patients with intracerebral hemorrhage. JAMA Neurol. 2016;73(8):961-8. https://doi. org/10.1001/jamaneurol.2016.1218.

24. Li Q, Zhang G, Huang YJ, Dong MX, Lv FJ, Wei X, et al. Blend sign on computed tomography: novel and reliable predictor for early hematoma growth in patients with intracerebral hemorrhage. Stroke. 2015;46(8):2119-23. https://doi.org/10.1161/STROKEAHA.115. 009185.

25. Gokce E, Beyhan M, Acu B. Evaluation of oral anticoagulantassociated intracranial parenchymal hematomas using CT findings. Clin Neuroradiol. 2015;25(2):151-9. https://doi.org/10.1007/s00062014-0292-8.

26. David J. Gladstone, Richard I. Aviv, Andrew M. Demchuk, Michael D. Hill, Kevin E. Thorpe, Jane C. Khoury et al. LB16randomized trial of hemostatic therapy for 'spot sign' positive intracerebral hemorrhage: primary results from the SPOTLIGHT/ STOP-IT study collaboration. 2017. http://www.abstractsonline. com/pp8/-!/4172/presentation/13152. Accessed June 5, 2017. Pooled analysis showing no benefit of early hemostatic therapy in patients with spot-sign.

27. Crash-trial collaborators, Shakur H, Roberts I, Bautista R, Caballero J, Coats T, et al. Effects of tranexamic acid on death, vascular occlusive events, and blood transfusion in trauma patients with significant haemorrhage (CRASH-2): a randomised, placebocontrolled trial. Lancet. 2010;376(9734):23-32. https://doi.org/10. 1016/S0140-6736(10)60835-5.
28. Parsons-Rich D, Hua F, Li G, Kantaridis C, Pittman DD, Arkin S. Phase 1 dose-escalating study to evaluate the safety, pharmacokinetics, and pharmacodynamics of a recombinant factor Xa variant (FXaI16L). J Thromb Haemost. 2017;15(5):931-7. https://doi.org/ 10.1111/jth.13673.

29. Thalji NK, Ivanciu L, Davidson R, Gimotty PA, Krishnaswamy S, Camire RM. A rapid pro-hemostatic approach to overcome direct oral anticoagulants. Nat Med. 2016;22(8):924-32. https://doi.org/10. 1038/nm.4149.

30. Gomez-Outes A, Lagunar-Ruiz J, Terleira-Fernandez AI, CalvoRojas G, Suarez-Gea ML, Vargas-Castrillon E. Causes of death in anticoagulated patients with atrial fibrillation. J Am Coll Cardiol. 2016;68(23):2508-21. https://doi.org/10.1016/j.jacc.2016.09.944.

31. Horstmann S, Rizos T, Lauseker M, Mohlenbruch M, Jenetzky E, Hacke W, et al. Intracerebral hemorrhage during anticoagulation with vitamin $\mathrm{K}$ antagonists: a consecutive observational study. J Neurol. 2013;260(8):2046-51. https://doi.org/10.1007/s00415013-6939-6.

32. Hanger HC, Fletcher VJ, Wilkinson TJ, Brown AJ, Frampton CM, Sainsbury R. Effect of aspirin and warfarin on early survival after intracerebral haemorrhage. J Neurol. 2008;255(3):347-52. https:// doi.org/10.1007/s00415-008-0650-z.

33. Flibotte JJ, Hagan N, O'Donnell J, Greenberg SM, Rosand J. Warfarin, hematoma expansion, and outcome of intracerebral hemorrhage. Neurology. 2004;63(6):1059-64.

34. Sarode R, Milling TJ Jr, Refaai MA, Mangione A, Schneider A, Durn BL, et al. Efficacy and safety of a 4-factor prothrombin complex concentrate in patients on vitamin $\mathrm{K}$ antagonists presenting with major bleeding: a randomized, plasma-controlled, phase IIIlb study. Circulation. 2013;128(11):1234-43. https://doi.org/10.1161/ CIRCULATIONAHA.113.002283.

35. Goldstein JN, Refaai MA, Milling TJ Jr, Lewis B, GoldbergAlberts R, Hug BA, et al. Four-factor prothrombin complex concentrate versus plasma for rapid vitamin $\mathrm{K}$ antagonist reversal in patients needing urgent surgical or invasive interventions: a phase $3 \mathrm{~b}$, open-label, non-inferiority, randomised trial. Lancet. 2015;385(9982):2077-87. https://doi.org/10.1016/S01406736(14)61685-8.

36. Steiner T, Poli S, Griebe M, Husing J, Hajda J, Freiberger A, et al. Fresh frozen plasma versus prothrombin complex concentrate in patients with intracranial haemorrhage related to vitamin $\mathrm{K}$ antagonists (INCH): a randomised trial. Lancet Neurol. 2016;15(6):56673. https://doi.org/10.1016/S1474-4422(16)00110-1. RCT showing a clear benefit of PCC over FFP in reversal of vitamin $\mathrm{K}$ antagonists associated $\mathrm{ICH}$.

37. Rizos T, Jenetzky E, Herweh C, Hug A, Hacke W, Steiner T, et al. Point-of-care reversal treatment in phenprocoumon-related intracerebral hemorrhage. Ann Neurol. 2010;67(6):788-93. https://doi. org/10.1002/ana.21965.

38. Laible M, Jenetzky E, Beynon C, Muller OJ, Sander P, Schuler S, et al. Adverse events following international normalized ratio reversal in intracerebral hemorrhage. Cerebrovasc Dis. 2016;42(5-6): 446-54. https://doi.org/10.1159/000448815.

39. Ruff CT, Giugliano RP, Braunwald E, Hoffman EB, Deenadayalu $\mathrm{N}$, Ezekowitz MD, et al. Comparison of the efficacy and safety of new oral anticoagulants with warfarin in patients with atrial fibrillation: a meta-analysis of randomised trials. Lancet. 2014;383(9921):955-62. https://doi.org/10.1016/S0140-6736(13) 62343-0.

40. Hart RG, Diener HC, Yang S, Connolly SJ, Wallentin L, Reilly PA, et al. Intracranial hemorrhage in atrial fibrillation patients during anticoagulation with warfarin or dabigatran: the RE-LY trial. Stroke. 2012;43(6):1511-7. https://doi.org/10.1161/ STROKEAHA.112.650614.

41. Lopes RD, Guimaraes PO, Kolls BJ, Wojdyla DM, Bushnell CD, Hanna M, et al. Intracranial hemorrhage in patients with atrial 
fibrillation receiving anticoagulation therapy. Blood. 2017;129(22): 2980-7. https://doi.org/10.1182/blood-2016-08-731638.

42. Purrucker JC, Haas K, Rizos T, Khan S, Wolf M, Hennerici MG, et al. Early clinical and radiological course, management, and outcome of intracerebral hemorrhage related to new oral anticoagulants. JAMA Neurol. 2016;73(2):169-77. https://doi.org/10.1001/ jamaneurol.2015.3682. Observational study showing hematoma expansion is frequent in NOAC-related ICH.

43. Wilson D, Seiffge DJ, Traenka C, Basir G, Purrucker JC, Rizos T, et al. Outcome of intracerebral hemorrhage associated with different oral anticoagulants. Neurology. 2017;88(18):1693-700. https://doi. org/10.1212/WNL.0000000000003886.

44. Purrucker JC, Rizos T, Haas K, Wolf M, Khan S, Heuschmann PU, et al. Coagulation testing in intracerebral hemorrhage related to non-vitamin $\mathrm{K}$ antagonist oral anticoagulants. Neurocrit Care. 2017; https://doi.org/10.1007/s12028-017-0403-x.

45. Ebner M, Birschmann I, Peter A, Spencer C, Hartig F, Kuhn J, et al. Point-of-care testing for emergency assessment of coagulation in patients treated with direct oral anticoagulants. Crit Care. 2017;21(1):32. https://doi.org/10.1186/s13054-017-1619-z.

46. Glund S, Stangier J, Schmohl M, Gansser D, Norris S, van Ryn J, et al. Safety, tolerability, and efficacy of idarucizumab for the reversal of the anticoagulant effect of dabigatran in healthy male volunteers: a randomised, placebo-controlled, double-blind phase 1 trial. Lancet. 2015;386(9994):680-90. https://doi.org/10.1016/S01406736(15)60732-2.

47. Glund S, Stangier J, van Ryn J, Schmohl M, Moschetti V, Haazen $\mathrm{W}$, et al. Effect of age and renal function on idarucizumab pharmacokinetics and idarucizumab-mediated reversal of dabigatran anticoagulant activity in a randomized, double-blind crossover phase $\mathrm{Ib}$ study. Clin Pharmacokinet. 2017;56(1):41-54. https://doi.org/10. 1007/s40262-016-0417-0.

48.• Pollack CV Jr., Reilly PA, van Ryn J, Eikelboom JW, Glund S, Bernstein RA, et al. Idarucizumab for dabigatran reversal - full cohort analysis. N Engl J Med. 2017;377(5):431-41. https://doi. org/10.1056/NEJMoa1707278. RCT demonstrating effective anticoagulation reversal by idarucizumab in patients treated with dabigatran.

49. Na SY, Mracsko E, van Ryn J, Veltkamp R. Idarucizumab improves outcome in murine brain hemorrhage related to dabigatran. Ann Neurol. 2015;78(1):137-41. https://doi.org/10.1002/ana.24421.

50.• Connolly SJ, Milling TJ Jr, Eikelboom JW, Gibson CM, Curnutte JT, Gold A, et al. Andexanet alfa for acute major bleeding associated with factor Xa inhibitors. N Engl J Med. 2016;375(12):1131-41. https://doi.org/10.1056/NEJMoa1607887. Important RCT showing efficacy of andexanet alfa for anticoagulation reversal of factor Xa inhibitors.

51. Gomez-Outes A, Suarez-Gea ML, Lecumberri R, TerleiraFernandez AI, Vargas-Castrillon E. Specific antidotes in development for reversal of novel anticoagulants: a review. Recent Pat Cardiovasc Drug Discov. 2014;9(1):2-10.

52. Ansell JE, Bakhru SH, Laulicht BE, Steiner SS, Grosso M, Brown $\mathrm{K}$, et al. Use of PER977 to reverse the anticoagulant effect of edoxaban. N Engl J Med. 2014;371(22):2141-2. https://doi.org/ 10.1056/NEJMc1411800.

53. Veltkamp R, Horstmann S. Treatment of intracerebral hemorrhage associated with new oral anticoagulant use: the neurologist's view. Clin Lab Med. 2014;34(3):587-94. https://doi.org/10.1016/j.cll. 2014.06.007.

54. Naidech AM, Maas MB, Levasseur-Franklin KE, Liotta EM, Guth $\mathrm{JC}$, Berman M, et al. Desmopressin improves platelet activity in acute intracerebral hemorrhage. Stroke. 2014;45(8):2451-3. https:// doi.org/10.1161/STROKEAHA.114.006061.

55. Baharoglu MI, Cordonnier C, Al-Shahi Salman R, de Gans K, Koopman MM, Brand A, et al. Platelet transfusion versus standard care after acute stroke due to spontaneous cerebral haemorrhage associated with antiplatelet therapy (PATCH): a randomised, open-label, phase 3 trial. Lancet. 2016;387(10038):2605-13. https://doi.org/10.1016/S0140-6736(16)30392-0.

56. Gregson BA, Broderick JP, Auer LM, Batjer H, Chen XC, Juvela S, et al. Individual patient data subgroup meta-analysis of surgery for spontaneous supratentorial intracerebral hemorrhage. Stroke. 2012;43(6):1496-504. https://doi.org/10.1161/STROKEAHA.111. 640284

57. Mendelow AD, Gregson BA, Fernandes HM, Murray GD, Teasdale GM, Hope DT, et al. Early surgery versus initial conservative treatment in patients with spontaneous supratentorial intracerebral haematomas in the International Surgical Trial in Intracerebral Haemorrhage (STICH): a randomised trial. Lancet. 2005;365(9457):387-97. https://doi.org/10.1016/S0140-6736(05) 17826-X.

58. Mendelow AD, Gregson BA, Rowan EN, Murray GD, Gholkar A, Mitchell PM, et al. Early surgery versus initial conservative treatment in patients with spontaneous supratentorial lobar intracerebral haematomas (STICH II): a randomised trial. Lancet. 2013;382(9890):397-408. https://doi.org/10.1016/S01406736(13)60986-1.

59.• Hanley DF, Thompson RE, Muschelli J, Rosenblum M, McBee N, Lane K, et al. Safety and efficacy of minimally invasive surgery plus alteplase in intracerebral haemorrhage evacuation (MISTIE): a randomised, controlled, open-label, phase 2 trial. Lancet Neurol. 2016;15(12):1228-37. https://doi.org/10.1016/S1474-4422(16) 30234-4. RCT suggesting that minimally invasive injection of rtPA into ICH might be beneficial.

60. Fiorella D, Arthur AS, Mocco JD. 305 The INVEST trial: a randomized, controlled trial to investigate the safety and efficacy of image-guided minimally invasive endoscopic surgery with Apollo vs best medical management for supratentorial intracerebral hemorrhage. Neurosurgery. 2016;63(Suppl 1):187. https://doi.org/10. 1227/01.neu.0000489793.60158.20.

61. Fiorella D, Arthur A, Bain M, Mocco J. Minimally invasive surgery for intracerebral and intraventricular hemorrhage: rationale, review of existing data and emerging technologies. Stroke. 2016;47(5): 1399-406. https://doi.org/10.1161/STROKEAHA.115.011415.

62. Tuhrim S, Horowitz DR, Sacher M, Godbold JH. Volume of ventricular blood is an important determinant of outcome in supratentorial intracerebral hemorrhage. Crit Care Med. 1999;27(3):617-21.

63. Morgan T, Awad I, Keyl P, Lane K, Hanley D. Preliminary report of the clot lysis evaluating accelerated resolution of intraventricular hemorrhage (CLEAR-IVH) clinical trial. Acta Neurochir Suppl. 2008; 105:217-20

64.• Hanley DF, Lane K, McBee N, Ziai W, Tuhrim S, Lees KR, et al. Thrombolytic removal of intraventricular haemorrhage in treatment of severe stroke: results of the randomised, multicentre, multiregion, placebo-controlled CLEAR III trial. Lancet. 2017;389(10069):603-11. https://doi.org/10.1016/S01406736(16)32410-2. Large RCT discussed controversially, not showing a clear benefit in terms of functional outcome and mortality of thrombolytic therapy in intraventricular hemorrhage.

65. Zhou Y, Wang Y, Wang J, Anne Stetler R, Yang QW. Inflammation in intracerebral hemorrhage: from mechanisms to clinical translation. Prog Neurobiol. 2014;115:25-44. https://doi.org/10.1016/j. pneurobio.2013.11.003.

66. Xi G, Keep RF, Hoff JT. Mechanisms of brain injury after intracerebral haemorrhage. Lancet Neurol. 2006;5(1):53-63. https://doi. org/10.1016/S1474-4422(05)70283-0.

67. Keep RF, Hua Y, Xi G. Intracerebral haemorrhage: mechanisms of injury and therapeutic targets. Lancet Neurol. 2012;11(8):720-31. https://doi.org/10.1016/S1474-4422(12)70104-7. 
68. Mracsko E, Veltkamp R. Neuroinflammation after intracerebral hemorrhage. Front Cell Neurosci. 2014;8:388. https://doi.org/10. 3389/fncel.2014.00388.

69. Cui HJ, He HY, Yang AL, Zhou HJ, Wang C, Luo JK, et al. Efficacy of deferoxamine in animal models of intracerebral hemorrhage: a systematic review and stratified meta-analysis. PLoS One. 2015;10(5):e0127256. https://doi.org/10.1371/journal.pone. 0127256.

70. Fu Y, Hao J, Zhang N, Ren L, Sun N, Li YJ, et al. Fingolimod for the treatment of intracerebral hemorrhage: a 2 -arm proof-of-concept study. JAMA Neurol. 2014;71(9):1092-101. https://doi.org/10. 1001/jamaneurol.2014.1065.

71. Khan NI, Siddiqui FM, Goldstein JN, Cox M, Xian Y, Matsouaka RA, et al. Association between previous use of antiplatelet therapy and intracerebral hemorrhage outcomes. Stroke. 2017; https:/doi. org/10.1161/STROKEAHA.117.016290.

72. Murthy SB, Gupta A, Merkler AE, Navi BB, Mandava P, Iadecola $\mathrm{C}$, et al. Restarting anticoagulant therapy after intracranial hemorrhage: a systematic review and meta-analysis. Stroke. 2017;48(6): 1594-600. https://doi.org/10.1161/STROKEAHA.116.016327.

73. Arima H, Chalmers J, Woodward M, Anderson C, Rodgers A, Davis S, et al. Lower target blood pressures are safe and effective for the prevention of recurrent stroke: the PROGRESS trial. J Hypertens. 2006;24(6):1201-8. https://doi.org/10.1097/01.hjh. 0000226212.34055 .86 .
74. SPS3 Study Group, Benavente OR, Coffey CS, Conwit R, Hart RG, McClure LA, et al. Blood-pressure targets in patients with recent lacunar stroke: the SPS3 randomised trial. Lancet. 2013;382(9891): 507-15. https://doi.org/10.1016/S0140-6736(13)60852-1.

75. Werring D. PROHIBIT-ICH. 2017. https://www.stroke.org.uk/ research/protecting-brain-after-bleed-home-monitored-bloodpressure-control. Accessed 24 Jun 2017.

76. Kazui S, Naritomi H, Yamamoto H, Sawada T, Yamaguchi T. Enlargement of spontaneous intracerebral hemorrhage. Incidence and time course. Stroke. 1996;27(10):1783-7.

77. Brott T, Broderick J, Kothari R, Barsan W, Tomsick T, Sauerbeck L, et al. Early hemorrhage growth in patients with intracerebral hemorrhage. Stroke. 1997;28(1):1-5.

78. Flaherty ML, Tao H, Haverbusch M, Sekar P, Kleindorfer D, Kissela B, et al. Warfarin use leads to larger intracerebral hematomas. Neurology. 2008;71(14):1084-9. https://doi.org/10.1212/01. wnl.0000326895.58992.27.

79. Cucchiara B, Messe S, Sansing L, Kasner S, Lyden P, Investigators C. Hematoma growth in oral anticoagulant related intracerebral hemorrhage. Stroke. 2008;39(11):2993-6. https://doi.org/10.1161/ STROKEAHA.108.520668.

80. Huhtakangas J, Tetri S, Juvela S, Saloheimo P, Bode MK, Hillbom $M$. Effect of increased warfarin use on warfarin-related cerebral hemorrhage: a longitudinal population-based study. Stroke. 2011;42(9): 2431-5. https://doi.org/10.1161/STROKEAHA.111.615260. 